This is the peer reviewed version of the following article: Medina, E. , Romero, C. and Brenes, M. (2018), Residual Olive Paste as a Source of Phenolic Compounds and Triterpenic Acids. Eur. J. Lipid Sci. Technol., 120: 1700368, which has been published in final form at https://doi.org/10.1002/ejlt.201700368. This article may be used for non-commercial purposes in accordance with Wiley Terms and Conditions for Self-Archiving.

\title{
Residual Olive Paste as a Source of Phenolic Compounds and Triterpenic Acids
}

\author{
Eduardo Medina; Concepción Romero; Manuel Brenes
}

Food Biotechnology Department, Instituto de la Grasa (IG-CSIC), Building 46, Ctra. Utrera km 1, 41013-Seville, Spain

\section{Abstract}

The two-phase centrifugation system of olive oil extraction produces huge amounts of olive pomace called alperujo that could be a good source of bioactive substances. However, alperujo is currently stored in open air ponds before it is dried and submitted for extraction of the residual oil. The aim of this work is to study the evolution of phenolic and triterpenic acids in alperujo during its storage and extraction processes on an industrial scale. Alperujo is stored in large open air ponds, dried and the residual oil is extracted with hexane over a course of a year for two consecutive olive seasons. The storage of alperujo did not cause great changes in the content of these substances in the paste although the pomace olive oil is enriched in triterpenic compounds, mainly oleanolic acid. By contrast, the drying and extraction steps gives rise to a great reduction in the concentration of phenolic compounds. Likewise, triterpenic acids are very stable during the extraction process, and an enrichment of them is detected in the extracted alperujo that can reach up to $7-8 \mathrm{~g} \mathrm{~kg}-1$ in these substances, particularly maslinic acid.

Practical Applications: There are many studies, methods, and patents to extract bioactive substances from olive by-products, particularly from the fresh olive pomace called alperujo. However, this study is the first to explore the stored and extracted alperujo as a good source of phenolic and triterpenic substances. Specifically, triterpenic acids were very stable during the storage and drying steps and extracted alperujo was highly enriched in them. This research will contribute to the valorization of olive by-products.

Extracted alperujo is a very good source of triterpenic acids.

\section{Introduction}

The two-phase centrifugation system for extracting olive oil is widely used in Spain and many other olive oil-producing countries. This method separates the oil from the wet olive paste, which is called alperujo in Spain. This by-product is generated for only 2-3 months a year in 
the olive oil mill factories and it is currently sent to an oil extraction plant where it is discharged into large open air ponds.1 Currently, stored alperujo is dried and subjected to chemical extraction with hexane to produce crude olive pomace oil, which must be refined before consumption.2 Finally, the dried and extracted alperujo is used for the co-generation of electrical power. However, this process is losing economic attractiveness due to the shortage in subsidies and the new practices carried out by olive oil mill factories such as exhausting the oil content in fresh alperujo and separating the stone components of this by-product before sending it to the oil extracting factories. Thus, new alternative uses have been proposed for alperujo, including composting, 3 soil amendment, 4 animal feed, 5 and as a source of bioactive substances.6, 7 In particular, alperujo is rich in phenolic compounds and triterpenic acids.8, 9

Phenolic and triterpenic substances have several biological activities, including antiinflammatory, antimicrobial, antioxidant, anti-diabetic, anti-tumor, hepato-protective, and cardio-protective activities. Among olive triterpenic acids, maslinic acid possesses anticoccidial activity 10 and favors growth of rainbow trout and gilthead sea bream11, 12 so its extracts are mainly marketed as feed additives. Moreover, hydroxytyrosol is the most prominent phenolic compound of virgin olive oil and table olives, possessing many beneficial properties for human health,13, 14 which is currently used as a therapeutic agent or dietary supplement around the world.

There are many methods and patents to extract these bioactive substances from olives, olive leaves, olive oil mill wastewaters, and fresh alperujo. However, the most abundant by-product generated by the olive oil industry is the stored alperujo, particularly the extracted alperujo. Natural biodegradation of the alperujo takes place in the ponds for months, provoked by the growth of different types of microorganisms, yeasts, molds and lactic acid bacteria, among others.15-17 In particular, strains of Lactobacillus pentosus are able to degrade p-coumaric acid to the off-odor 4-ethyphenol,18 which is concentrated in the oily phase.18, 19 Specifically, the oily phase is also enriched in triterpenic acids over the time alperujo stays in the ponds. 20 However, to our knowledge, no data is available on the evolution of phenolic and triterpenic compounds in whole alperujo with time of storage. Likewise, stored alperujo is submitted to a drying process before residual oil extraction with hexane, and the chemical degradation that these bioactive substances could undergo during this stage has not been reported. Hence, the aim of this work was to discover whether the extracted alperujo is a good source of these bioactive substances as well as to assess the changes that these compounds undergo during both the storage phase in the open air ponds and the extracting process.

\section{Experimental Section}

\subsection{Samples}

They were obtained from the facilities of the alperujo oil extracting plant San Miguel Arcángel, S. A. (Jaén, Spain). This factory processes around 500000 tons of alperujo per year, stored in five large ponds. Throughout the year, the stored alperujo is submitted to a drying process in a drying drum with hot air at a temperature of around $400-800^{\circ} \mathrm{C} .1$ Subsequently, the residual oil is extracted with hexane from the dry alperujo, and a desolventization step is required at a temperature below $110^{\circ} \mathrm{C}$ to remove all residual solvent from the dry and extracted alperujo.21 Thousands of tons of stored alperujo were taken out of the ponds every day and 
processed. Representative samples of stored alperujo (1 kg), dry and extracted alperujo (1 kg), and crude alperujo oil ( $1 \mathrm{~kg}$ ) were submitted every month to the laboratory of the Instituto de la Grasa from December to September during the 2012/2013 and 2013/2014 seasons. They were analyzed immediately without any storage period.

\subsection{Analysis of Phenolic Compounds}

\subsubsection{Alperujo Paste}

The extraction of phenolic compounds from alperujo was based on the methodology reported elsewhere.22 Around $10 \mathrm{~g}$ of fresh alperujo was mixed in an Ultra-Turrax homogenizer (Ika, Breisgau, Germany) with $30 \mathrm{~mL}$ of dimethyl sulfoxide (DMSO). After $30 \mathrm{~min}$ of resting contact, the mixture was centrifuged at $6000 \times \mathrm{g}$ for $5 \mathrm{~min}\left(22^{\circ} \mathrm{C}\right)$ and $0.25 \mathrm{~mL}$ of the supernatant was diluted with $0.5 \mathrm{~mL}$ of DMSO plus $0.25 \mathrm{~mL}$ of $0.2 \mathrm{mM}$ of syringic acid in DMSO (internal standard).

Samples were filtered through a $0.22 \mu \mathrm{m}$ pore size nylon filter, and an aliquot ( $20 \mu \mathrm{L}$ ) was injected into the chromatograph. The chromatographic system consisted of a Waters 717 plus autosampler, a Waters 600 pump, a Waters column heater module, and a Waters 996 photodiode array detector operated with Empower2 software (Waters, Mildford, USA). A $25 \mathrm{~cm} \times 4.6 \mathrm{~mm}$ i. d., $5 \mu \mathrm{m}$, Spherisob ODS-2 (Waters, Inc.) column, at a flow rate of $1 \mathrm{~mL}$ min-1 and a temperature of $35^{\circ} \mathrm{C}$, was used in all experiments. Separation was achieved by gradient elution using (A) water ( $\mathrm{pH} 2.5$ adjusted with $0.15 \%$ phosphoric acid) and (B) methanol. The initial composition was $90 \% \mathrm{~A}$ and $10 \% \mathrm{~B}$. The concentration of $\mathrm{B}$ was increased to $30 \%$ over $10 \mathrm{~min}$ and was maintained for $20 \mathrm{~min}$. Subsequently, B was raised to $40 \%$ over $10 \mathrm{~min}$, maintained for $5 \mathrm{~min}$, and then increased to $50 \%$. Finally, B was increased to 60,70 , and $100 \%$ in 5 -min periods. The initial conditions were reached in $10 \mathrm{~min}$. Chromatograms were recorded at $280 \mathrm{~nm}$.

The evaluation of each compound was performed using a regression curve with the corresponding standard. Hydroxytyrosol was purchased from Extrasynthese S. A. (Genay, France) and tyrosol, catechol, vanillin, 4-ethylphenol, and vanillic acid from Sigma Chemical Co. (St Louis, USA). Hydroxytyrosol acetate was quantified using the response factors of hydroxytyrosol. The dialdehydic form of decarboxymethyl elenolic acid linked to hydroxytyrosol (HyEDA), pinoresinol and 1-acetoxy pinoresinol were obtained using a HPLC preparative system. 23

\subsubsection{Alperujo Oil}

They were extracted from the oil with N,N-dimethylformamide (DMF).23 Briefly, $0.6 \mathrm{~g}$ of oil was extracted with $3 \times 0.6 \mathrm{~mL}$ of DMF; the extract was then washed with hexane, and N2 was bubbled into the DMF extract to eliminate residual hexane. Syringic acid $(0.2 \mathrm{~mm})$ was employed as internal standard. Finally, the extract was filtered through a $0.22 \mu \mathrm{m}$ pore size nylon filter and injected into the chromatograph.

The chromatographic system was the same as noted above, except that a fluorescence detector was put in series with a DAD detector to monitor all phenolic compounds. 


\subsection{Analysis of Triterpenic Acids}

\subsubsection{Alperujo Paste}

Ten grams of alperujo were desiccated at $105^{\circ} \mathrm{C}$ until weight stabilization. Subsequently, $1 \mathrm{~g}$ of dry and triturated alperujo was mixed in a $10 \mathrm{~mL}$ centrifuge tube with $4 \mathrm{~mL}$ of methanol/ethanol $(1: 1, \mathrm{v} / \mathrm{v})$ and vortexed for $1 \mathrm{~min}$, centrifuged at $6000 \times \mathrm{g}$ for $5 \mathrm{~min}$ at $20^{\circ} \mathrm{C}$, and the solvent was separated from the solid phase. This step was repeated six times, and the pooled solvent extract was vacuum evaporated. The residue was dissolved in $2 \mathrm{~mL}$ of methanol, which was filtered through a $0.22 \mu \mathrm{m}$ pore size nylon filter and an aliquot $(20 \mu \mathrm{L})$ was injected into the liquid chromatograph.24 The chromatographic system and column were the same as those used for the phenolic compound analysis. The mobile phase (methanol/acidified water with phosphoric acid at $\mathrm{pH} 3.0,92: 8, \mathrm{v} / \mathrm{v}$ ) was delivered to the column at a flow rate of $0.8 \mathrm{~mL} \mathrm{~min}-1$ and the eluate was monitored at $210 \mathrm{~nm} .20$ Oleanolic and maslinic acids were quantified using external standards (Sigma, USA).

\subsubsection{Alperujo Oil}

The extraction of these substances from alperujo oil was performed using a mixture of methanol/ethanol (1:1).20 The oil $(0.8 \mathrm{~g})$ and the alcoholic solvent $(1.6 \mathrm{~mL})$ were vortexed for $1 \mathrm{~min}$, centrifuged at $6000 \times \mathrm{g}$ for $5 \mathrm{~min}$ at $20^{\circ} \mathrm{C}$, and the alcoholic phase was separated from the lipid phase. This step was repeated six times. Subsequently, the pooled alcoholic extract was vacuum evaporated and the residue dissolved in $2.4 \mathrm{~mL}$ methanol, which was centrifuged at $6000 \times \mathrm{g}$ for $5 \mathrm{~min}$ at $20^{\circ} \mathrm{C}$. Finally, the solution was filtered through $0.22 \mu \mathrm{m}$ pore size nylon filter and an aliquot $(20 \mu \mathrm{L})$ was injected into the liquid chromatograph. The chromatographic system and column were the same as described above.

\subsection{Determination of $\mathrm{pH}$}

The $\mathrm{pH}$ values of stored alperujo were measured with a Crison Basic $20 \mathrm{pH}$-meter.

\subsection{Determination of Moisture}

The water content of alperujo was determined by weighing $10 \mathrm{~g}$ of the paste and then oven drying at $105^{\circ} \mathrm{C}$ to constant weight.

\section{Results and Discussion}

Figure 1 shows the evolution of the $\mathrm{pH}$ in the alperujo paste during its storage in the open air ponds for two consecutive seasons. There was a steady decrease of this parameter from values around 5.0-5.2 to 4.3-4.5 after 8-10 months of storage, which must have been related to the growth of several types of microorganisms producing acidic substances such as acetic and lactic acid.18 In addition, off-odor 4-ethylphenol was found in the pomace oil from the beginning of storage (Table 1 ) as a consequence of L. pentosus growth and degradation of $p$ coumaric acid. It must be noted that this substance is concentrated in the oily phase of the alperujo and its formation can be inhibited by lowering the $\mathrm{pH}$ of the paste below 2-3 units19, 25 thereby inhibiting growth of L. pentosus. The content of hydroxytyrosol and hydroxytyrosol acetate in the oil did not show a clear trend with time of storage whereas tyrosol, catechol, 
pinoresinol, and others tended to increase with time (Table 1). Many beneficial properties have been attributed to these substances, in particular hydroxytyrosol, but most of them are removed during the mandatory refining of the oil before consumption. 2

Triterpenic acids are other bioactive substances that increased their content in the pomace oil with time of storage (Figure 2), particularly oleanolic acid due to its higher solubility in hexane than maslinic acid. A concentration of triterpenic acids close to $5 \mathrm{~g} \mathrm{~kg}-1$ oil can be reached in this oil although these substances are also lost during refining of the oil.26 However, this crude pomace oil can be a good source of triterpenic acids, although the presence of the off-odor 4ethylphenol could limit the use of the extracts for human food consumption.

As mentioned, fresh alperujo is stored in open air ponds where rain currently falls throughout the storage period, which could give rise to an increase in the moisture of the paste. However, the ponds are so huge that the moisture of the alperujo that fed the extraction plant was almost constant for months, around $70 \%$ for the two seasons analyzed (Figure $\underline{3}$ ). In addition, the moisture of the extracted alperujo was also very constant, around $10 \%$ for the two seasons. It has been reported that low moisture of the paste is necessary for a good extraction of the residual oil with hexane 1 and it was performed during the two seasons. It must be noted that desiccation of the alperujo is achieved at very high temperatures $\left(400-800^{\circ} \mathrm{C}\right)$ and it could contribute to the transformation of the bioactive substances contained in the paste.

Although oleanolic acid was stable at $95{ }^{\circ} \mathrm{C}$ during its extraction from plants, 27 stability of both maslinic and oleanolic acid at the very high temperatures $\left(400-800^{\circ} \mathrm{C}\right)$ employed during the desiccation step has never been explored. Surprisingly, degradation of these substances was not observed during extraction of the residual oil (Figure 4). It must be said that the concentration of both maslinic and oleanolic acid in the alperujo before extraction was rather constant throughout the storage period and between seasons. The content of maslinic and oleanolic acid ranged from around $1500-2000$ and $800-1000 \mathrm{mg} \mathrm{kg}^{-1}$, respectively. Moreover, the concentration of maslinic acid increased threefold in the extracted alperujo, rising up to $4000-7000 \mathrm{mg} \mathrm{kg}^{-1}$. Taking into consideration the moisture of the alperujo before and after the extraction (Figure $\underline{3}$ ) and the concentration of maslinic acid in the pastes (Figure $\underline{4}$ ), it can be deduced from a mass balance that this substance remained unaltered during the drying step at very high temperatures $\left(400-800^{\circ} \mathrm{C}\right)$. With regard to oleanolic acid, this substance was also concentrated in the extracted and dried alperujo, but less than threefold, which is probably due to its higher solubility in hexane than maslinic acid and therefore its higher content in the pomace olive oil (Figure 2).

Hydroxytyrosol was the major phenolic compound quantified in alperujo before and after the extraction process (Figure 5). Its content in un-extracted alperujo ranged around 2000 and $1000 \mathrm{mg} \mathrm{kg}^{-1}$ during the seasons 2012/2013 and 2013/2014, respectively. This simple phenol is not present in harvested olives, but it is part of more complex molecules such as oleuropein, hydroxytyrosol glucosides, or verbascoside.24 During the crushing and malaxation steps of the olive oil extraction process, most oleuropein is enzymatically hydrolyzed into phenolic aglycons and a small proportion of them are transferred to the oily phase. 28 In addition, chemical and enzymatic hydrolysis of compounds containing hydroxytyrosol may occur during alperujo 
storage in a similar manner, as happens during storage of olive oil mill wastewater. 29 However, considering the high concentration of oleuropein and hydroxytyrosol glucosides in harvested olives $\underline{22}$ and the low concentration of hydroxytyrosol in the alperujo (1000$2000 \mathrm{mg} \mathrm{kg}^{-1}$ ) (Figure 5 ), it is clear that most of this 0 -diphenol was lost mainly due to enzymatic oxidation during the malaxation and further manipulation steps of the paste.

In contrast to triterpenic acids, the concentration of hydroxytyrosol was rather similar in unextracted and extracted alperujo, which means that a high amount of this bioactive substance was lost during the drying and extraction steps. This o-diphenol is likely to be chemically oxidized at the high temperature used during the drying step $\left(400-800^{\circ} \mathrm{C}\right)$. Although the $\mathrm{pH}$ of the un-extracted alperujo was less than five units (Figure 1), the chemical oxidation of odiphenols is highly accelerated by increasing temperature, so that most of this substance was lost during extraction. However, a concentration of $1000-2000 \mathrm{mg} \mathrm{kg}-1$ of hydroxytyrosol remained in extracted alperujo, which is similar to that reported in many olive oil mill wastewaters and olive pomace sources for industrial extraction of hydroxytyrosol.

Other phenolic compounds identified in alperujo were hydroxytyrosol glycol, hydroxytyrosol acetate, tyrosol, vanillic acid, luteolin, apigenin, caffeic acid, verbascoside, p-coumaric, and the dialdehydic form of decarboxymethyl elenolic acid linked to hydroxytyrosol (HyEDA). The concentration of all of them ranged around 800 and $500 \mathrm{mg} \mathrm{kg}-1$ during the seasons 2012/2013 and 2013/2014, respectively. However, verbascoside and HyEDA were not detected after February and a slight increase in tyrosol and hydroxytyrosol glycol content was observed with time of alperujo in the ponds. Similarly to hydroxytyrosol, the amount of these substances was rather similar in un-extracted and extracted alperujo, which indicated that they also suffered oxidation and degradation reactions during the extraction process. Most of them have an o-diphenol structure so they are very prone to oxidation.

\section{Conclusions}

Pomace olive oil was enriched in triterpenic acids throughout the storage of the alperujo in the ponds, oleanolic acid being the majority due mainly to its higher solubility in hexane than maslinic acid.

The triterpenic acids maslinic and oleanolic were very stable during storage of alperujo in large open air ponds for 8-10 months, their concentration being very constant during the two seasons studied. Furthermore, they remained unaltered after the drying and extraction steps, thereby they were concentrated in the extracted alperujo by up to $7-8 \mathrm{~g} \mathrm{~kg}-1$. In contrast, a high amount of phenolic compounds, in particular hydroxytyrosol, was lost during these steps due probably to their oxidation at the high temperature employed. Hence, the high concentration of triterpenic acids found in extracted alperujo, particularly maslinic acid, together with the phenolic compound hydroxytyrosol, opens a door to the exploitation of this material as a good source of bioactive substances. 


\section{Acknowledgements}

The authors are grateful to San Miguel Arcángel, S. A. for the supply of olive material. This work was supported by the Spanish Government and European Feder funds (project ASOAN, Interconecta ITC-20111073). The authors thank Alejandra Expósito for technical assistance.

\section{Conflict of Interest}

The authors declare no conflict of interest. 


\section{References}

1 Sánchez, P., Ruíz-Méndez, M. V., Grasas Aceites 2006, 57, 47.

2 García, A., Ruíz-Méndez, M. V., Romero, C., Brenes, M., J. Am.Oil Chem. Soc. 2006, 83, 159.

3 Cayuela, M. L., Sánchez-Monedero, M. A., Roig, A., Biodegrad 2010, 21, 465.

4 Killi, D., Anlauf, R., Kavdir, Y., Haworth, M., Int. Biodeter. Biodegrad. 2014, 94, 48.

5 Nasopoulou, C., Stamatakis, G., Demopoulos, C. A., Zabetakis, I., Food Chem. 2011, 129, 1108.

6 Roig, A., Cayuela, M. L., Sánchez-Monedero, M. A., Waste Manage. 2006, 26, 960.

7 Sedej, I., Milczarek, R., Wang, S., Sheng, R., Avena-Bustillos, R. J., Dao, L., Takeoka, G., J. Food Sci. 2016, 81, E889.

8 Artajo, L. S., Romero, M. P., Suárez, M., Motilva, M. J., Eur. Food Res. Technol. 2007, 225, 617.

9 Fernández-Hernández, A., Martínez, A., Rivas, F., García-Mesa, J. A., Parra, A., J. Agric. Food Chem. 2015, 63, 4269.

10 Rambozzi, L., Odore, R., Min, A. R. M., Gardini, G., Mimosi, A., Comale, P., Large Anim. Rev. 2016, 22, 19.

11 Fernández-Navarro, M., Peragón, J., Esteban, F. J., Comp. Biochem. Phys. C 2006, 144, 130.

12 Gisbert, E., Andreee, K. B., Quintela, J. C., Calduch-Giner, J. A., Ipharraguerre, I. R., PérezSánchez, J., British J. Nutr. 2017, 117, 351.

$13 \mathrm{Hu}$, T., He, X. W., Jiang, J. G., Xu, X. L., J. Agric. Food Chem. 2014, 62, 1449.

14 Nunes, M. A., Pimentel, F. B., Costa, A. S. G., Alves, R. C., Oliveira, M. B. P. P., Innov. Food Sci. Emerg Technol. 2016, 35, 139.

15 Giannoutsou, E. P., Meintanis, C., Karagouni, A. D., Biores. Technol. 2004, 93, 301.

16 Ntougias, S., Bourtzis, K., Tsiamis, G., BioMed Res. Int. 2013, ID 784591.

17 Tortosa, G., Castellano-Hinojosa, A., Correa-Galeote, D., Bedmar, E. J., Biores. Technol. 2017, 224, 101.

18 De Castro, A., Asencio, E., Ruíz-Méndez, M. V., Romero, C., Brenes, M., J. Sci. Food Agric. $2015,95,2222$.

19 Ruiz-Méndez, M. V., Romero, C., Medina, E., García, A., de Castro, A., Brenes, M., J. Am.Oil Chem. Soc. 2013, 90, 401. 
20 García, A., Brenes, M., Dobarganes, M. C., Romero, C., Ruiz-Méndez, M. V., Eur. J. Lipid Sci. Technol. 2008, 110, 1136.

21 A. Demarco, in Extracción con solvente in Temas selectos en aceites y grasas,AOCS, (Eds: J. M. Block, D. Barrera-Arellano), Editorial Edgard Blücher Lta. Sao Pablo, Brasil 2009, pp. 67-97.

22 Ramírez, E., Medina, E., Brenes, M., Romero, C., J. Agric. Food Chem. 2014, 62, 9569.

23 García, A., Brenes, M., Romero, C., García, P., Garrido, A., Int. J. Food Sci. Technol. 2002, 37, 615.

24 Romero, C., Medina, E., Mateo, M. A., Brenes, M., J. Sci. Food Agric. 2017, 97, 1725.

25 Brenes, M., Romero, C., García, A., Hidalgo, F. J., Ruíz-Méndez, M. V., J. Agri. Food Chem. $2004,52,8177$.

26 Sánchez-Gutiérrez, C. A., Ruiz-Méndez, M. V., Jiménez-Castellanos, M. R., Lucero, M. J., Eur. J. Lipid Sci. Technol. 2017, 119, n/a 1600408.

27 Mandal, V., Mandal, S. C., Biochem. Eng. J. 2010, 50, 63.

28 Klen, T. J., Wondra, A. G., Vrhovšek, U., Sivilotti, P., Vodopivec, B. M., J. Agric. Food Chem. $2015,63,4570$.

29 Feki, M., Allouche, N., Bouaziz, M., Gargoubi, A., Sayadi, S., Eur. J. Lipid Sci. Technol. 2006, 108, 1021. 


\section{Figure legends}

Figure 1. Evolution of $\mathrm{pH}$ in stored alperujo before extraction of the residual oil.

Figure 2. Evolution of triterpenic acids in the pomace oil extracted from stored alperujo during the season 2013/2014. Where standard error bars are not visible, determinations were within range of symbols on graph.

Figure 3. Moisture of stored alperujo before and after the extraction of the residual oil. Season 2013/2014 (t, n); season 2013/2014 (I, \$). Where standard error bars are not visible, determinations were within range of symbols on graph.

Figure 4. Concentration of triterpenic acids in stored alperujo before (BE) and after ( $A E$ ) the extraction of the residual oil throughout the seasons 2012/2013 and 2013/2014. Bars mean the standard deviation.

Figure 5. Concentration of phenolic compounds in stored alperujo before and after the extraction of the residual oil. Others is the sum of hydroxytyrosol glycol, hydroxytyrosol acetate, tyrosol, vanillic acid, luteolin, apigenin, caffeic acid, verbascoside, p-coumaric, and the dialdehydic form of decarboxymethyl elenolic acid linked to hydroxytyrosol (HyEDA). Bars mean the standard deviation. 
Table 1. Phenolic compounds ( $\mathrm{mg} \mathrm{kg}^{-1}$ oil) in pomace oil extracted from stored alperujo during the season 2013/2014

\begin{tabular}{|c|c|c|c|c|c|c|c|c|}
\hline Date & $\begin{array}{l}\text { Hydroxytyro } \\
\text { sol }\end{array}$ & $\begin{array}{l}\text { Hydroxytyro } \\
\text { sol acetate }\end{array}$ & $\begin{array}{l}\text { Tyros } \\
\text { ol }\end{array}$ & $\begin{array}{l}\text { Catech } \\
\text { ol }\end{array}$ & $\begin{array}{l}\text { 4- } \\
\text { Ethylphe } \\
\text { nol }\end{array}$ & $\begin{array}{l}\text { Pinoresi } \\
\text { nol }\end{array}$ & $\begin{array}{l}\text { Other } \\
\mathrm{s}^{\mathrm{a}}\end{array}$ & $\begin{array}{l}\text { Tot } \\
\text { al }\end{array}$ \\
\hline $\begin{array}{l}\text { Decemb } \\
\text { er }\end{array}$ & $137(6)^{b}$ & $131(29)$ & $34(4)$ & $11(2)$ & $91(10)$ & $106(11)$ & $25(3)$ & $\begin{array}{l}535 \\
(49)\end{array}$ \\
\hline January & $152(1)$ & $90(2)$ & $34(1)$ & $8(1)$ & $33(1)$ & $74(1)$ & $16(2)$ & $\begin{array}{l}407 \\
(10)\end{array}$ \\
\hline $\begin{array}{l}\text { Februar } \\
\text { y }\end{array}$ & $163(38)$ & $167(25)$ & $44(4)$ & $25(4)$ & $48(3)$ & $46(7)$ & $13(4)$ & $\begin{array}{l}506 \\
(85)\end{array}$ \\
\hline March & $115(7)$ & $118(8)$ & $52(1)$ & $27(1)$ & $54(1)$ & $41(2)$ & $19(5)$ & $\begin{array}{l}426 \\
(11)\end{array}$ \\
\hline April & $95(2)$ & $67(1)$ & $70(2)$ & $89(2)$ & 89 (1) & $17(2)$ & $\begin{array}{l}278 \\
(34)\end{array}$ & $\begin{array}{l}705 \\
\text { (39) }\end{array}$ \\
\hline May & $60(12)$ & $44(8)$ & $56(4)$ & $37(5)$ & $75(5)$ & 137 (17) & $\begin{array}{l}80 \\
(25)\end{array}$ & $\begin{array}{l}489 \\
(86)\end{array}$ \\
\hline June & 109 (12) & $72(2)$ & $71(1)$ & 75 (11) & $94(4)$ & $134(9)$ & $\begin{array}{l}161 \\
(12)\end{array}$ & 716 \\
\hline
\end{tabular}

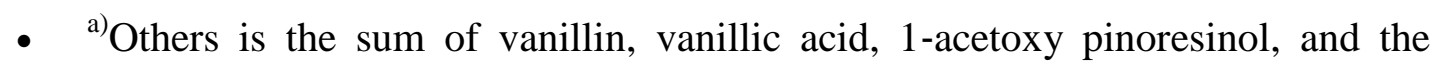
dialdehydic form of decarboxymethyl elenolic acid linked to hydroxytyrosol

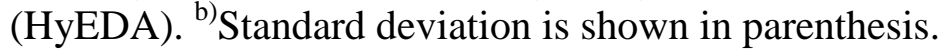


Figure 1

$\neg$ Season 2012/2013 $\rightarrow$-Season 2013/2014

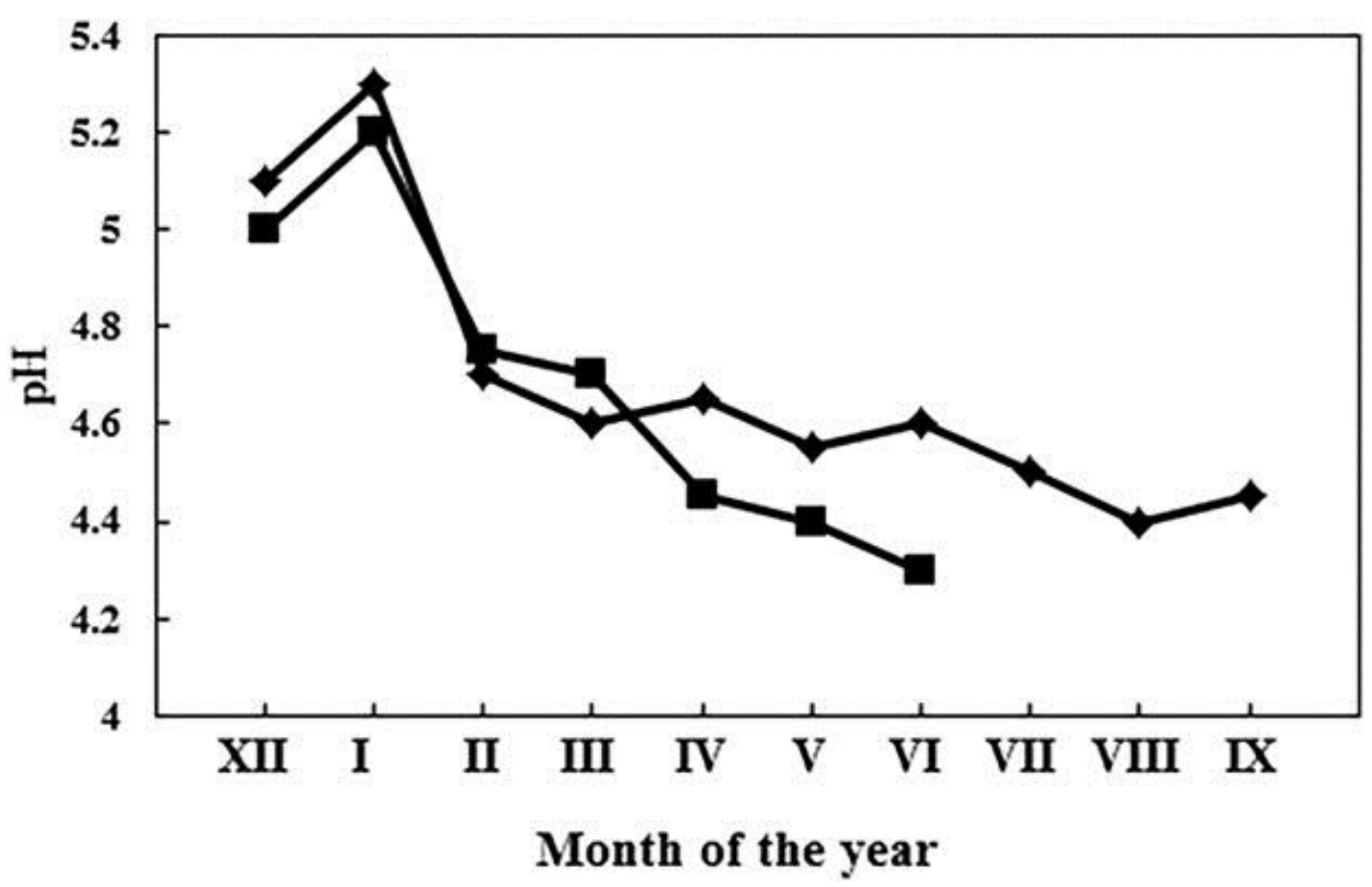


Figure 2

$\rightarrow$ maslinic acid $\rightarrow$-oleanolic acid

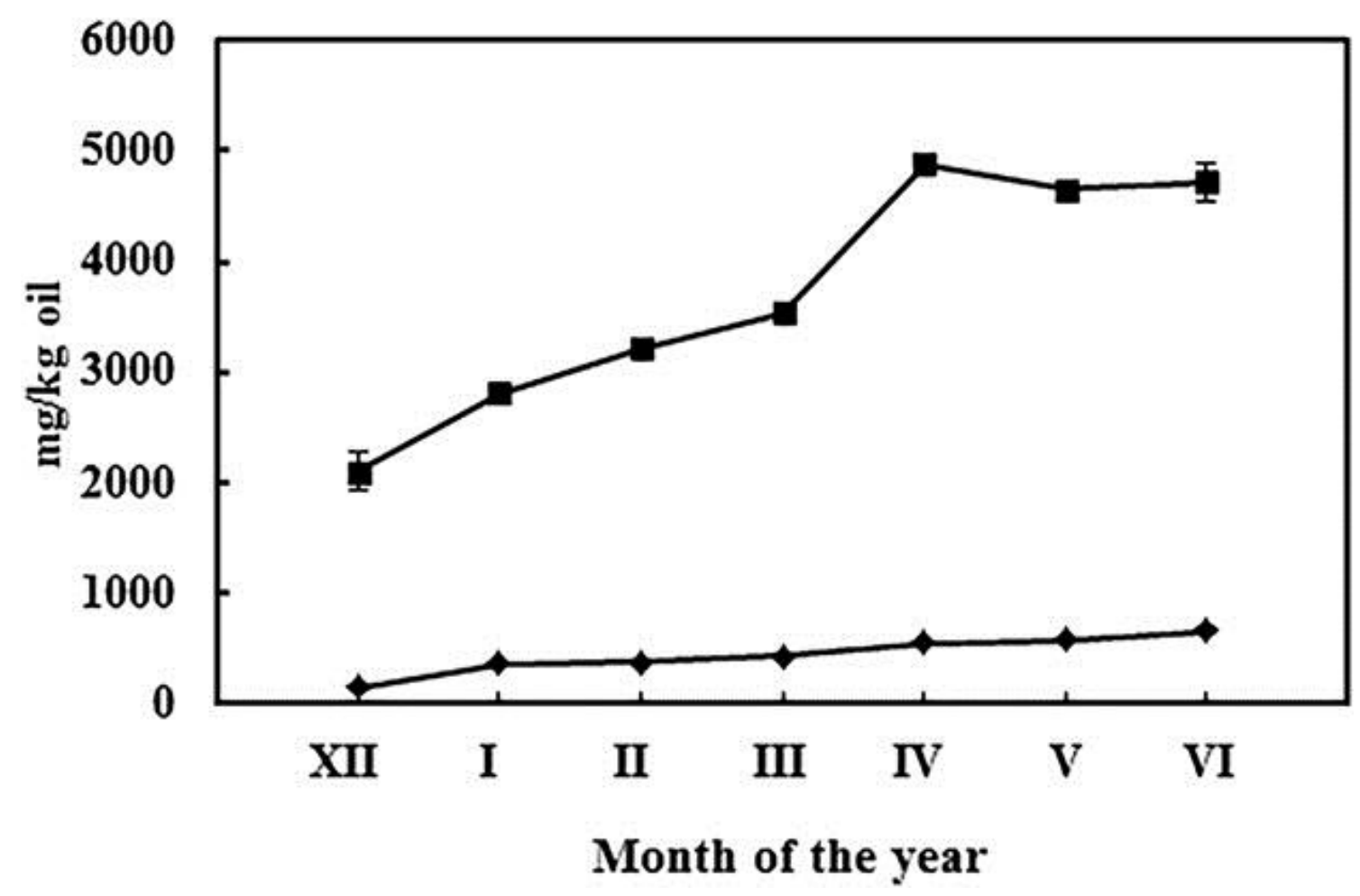


Figure 3

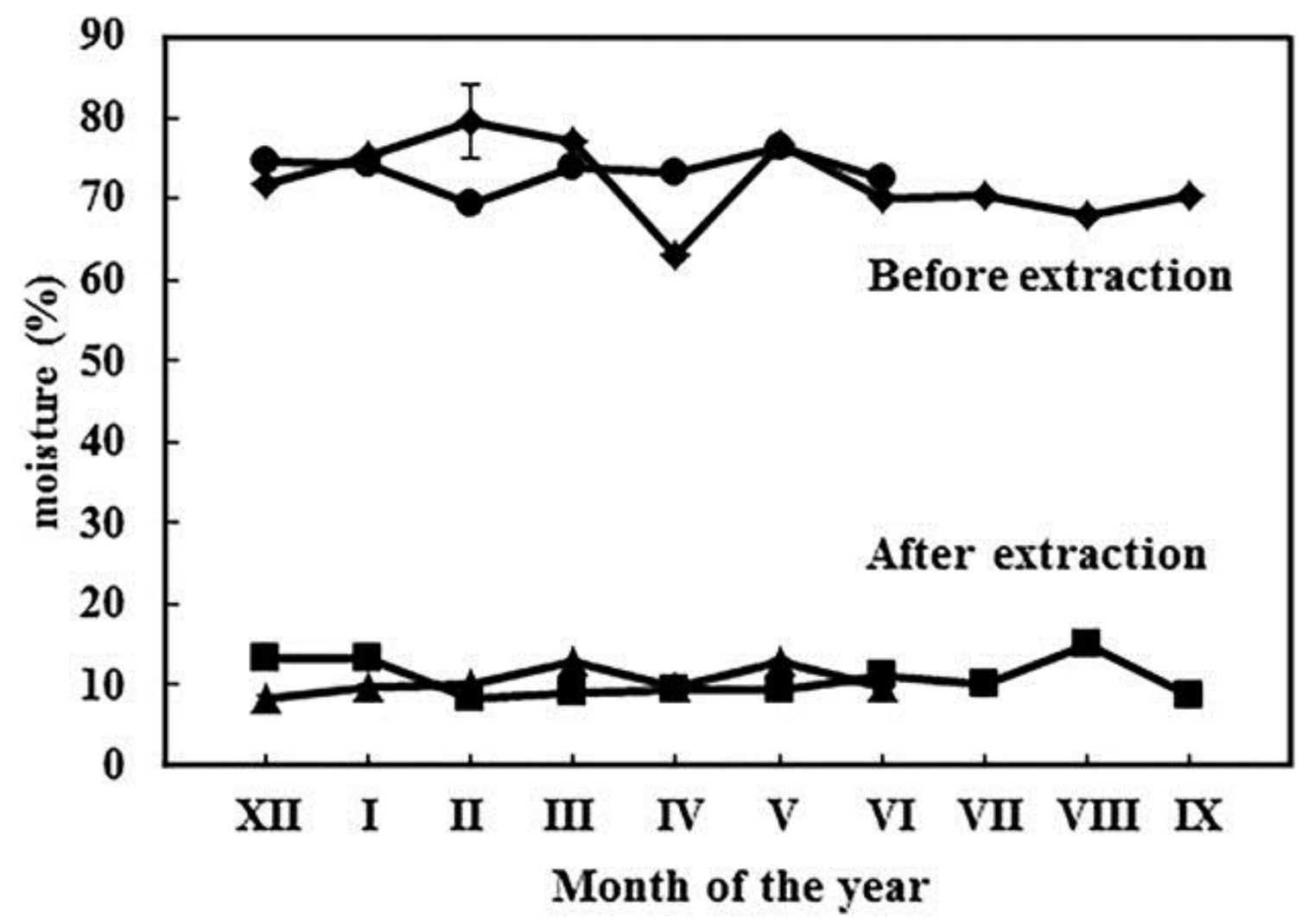


Figure 4

$\bullet$ maslinic BE Doleanolic BE Omaslinic AE $\Delta$ oleanolic AE

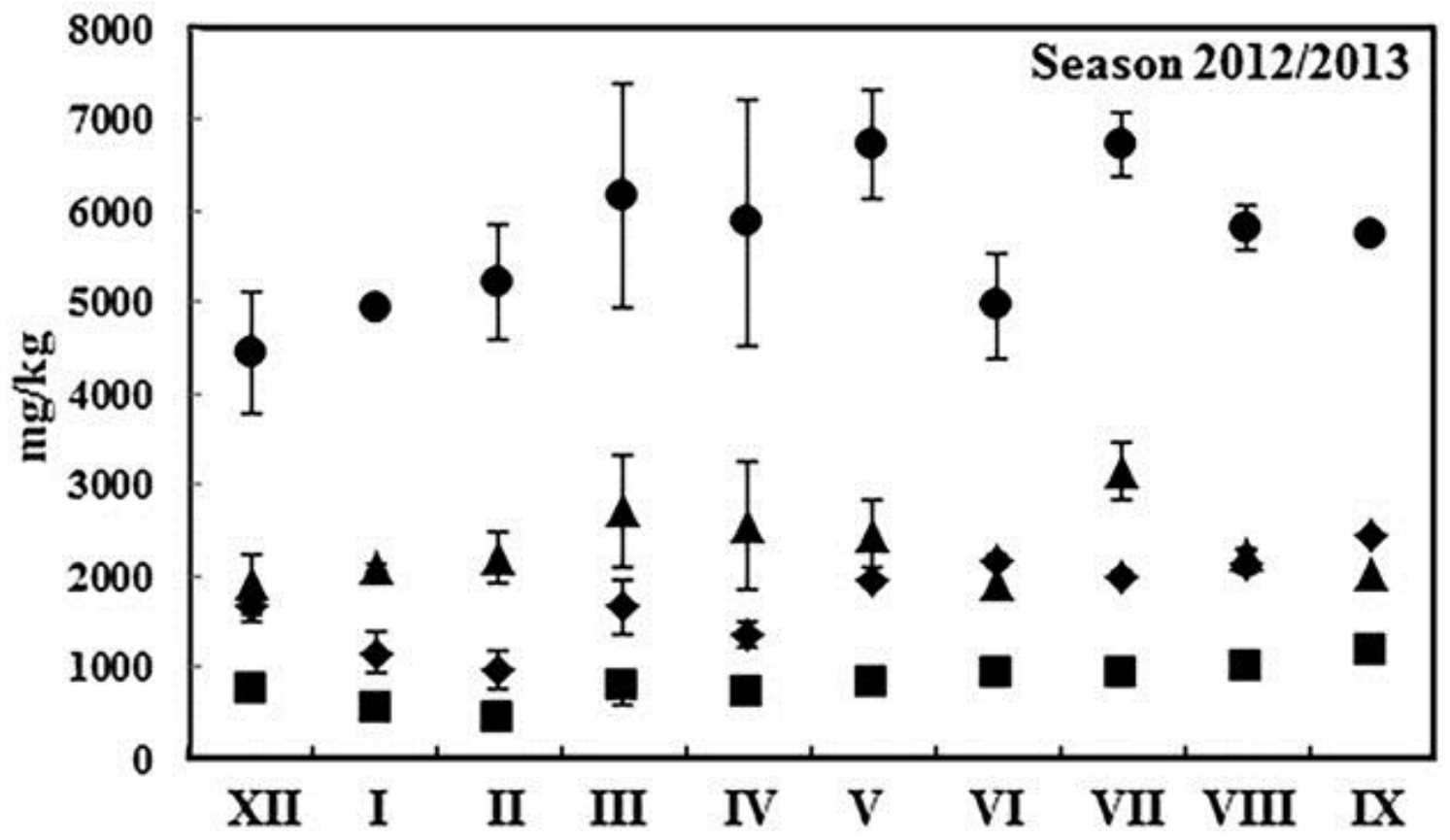

$\diamond$ maslinic BE Doleanolic BE Omaslinic AE $\Delta$ oleanolic AE

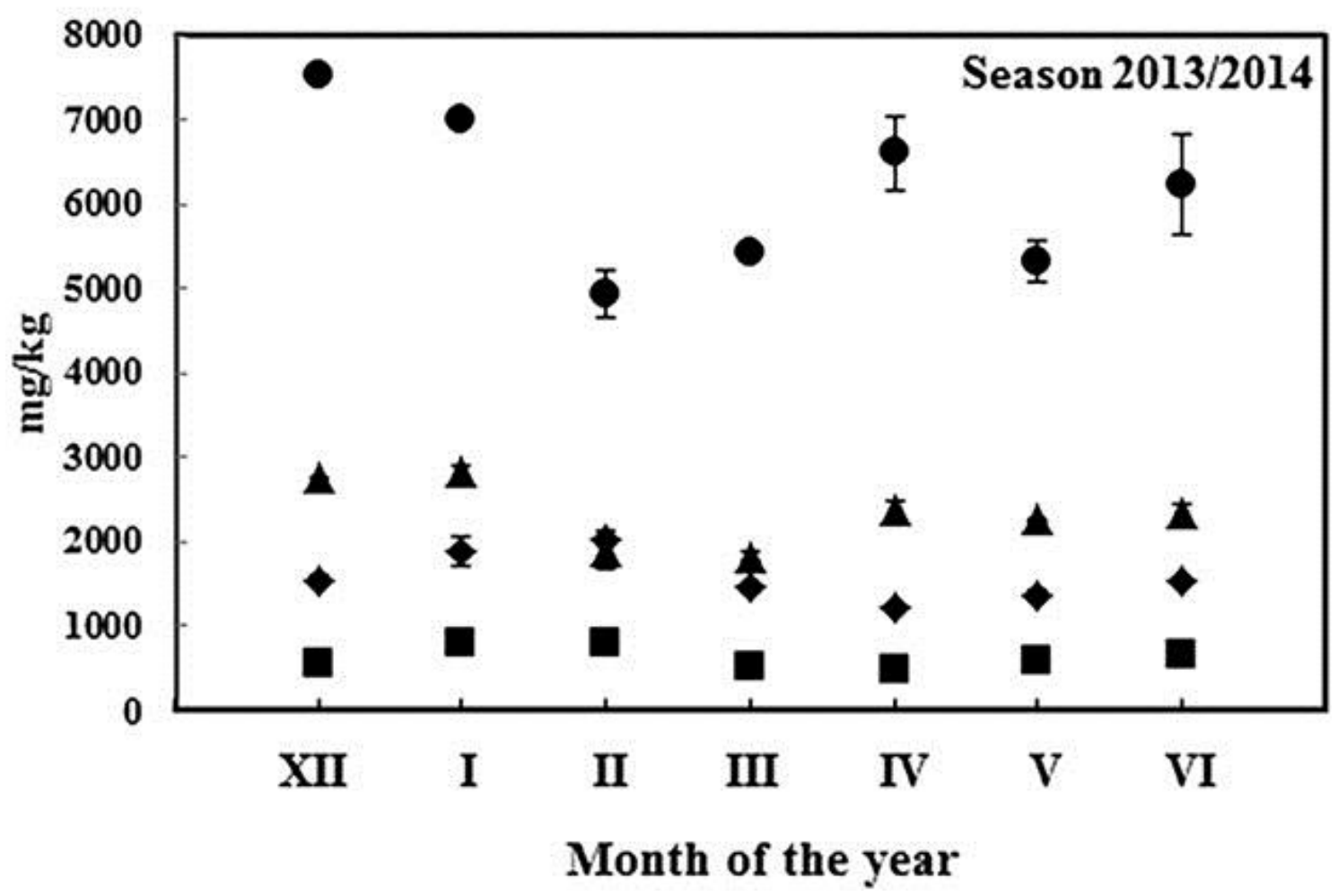


Figure 5
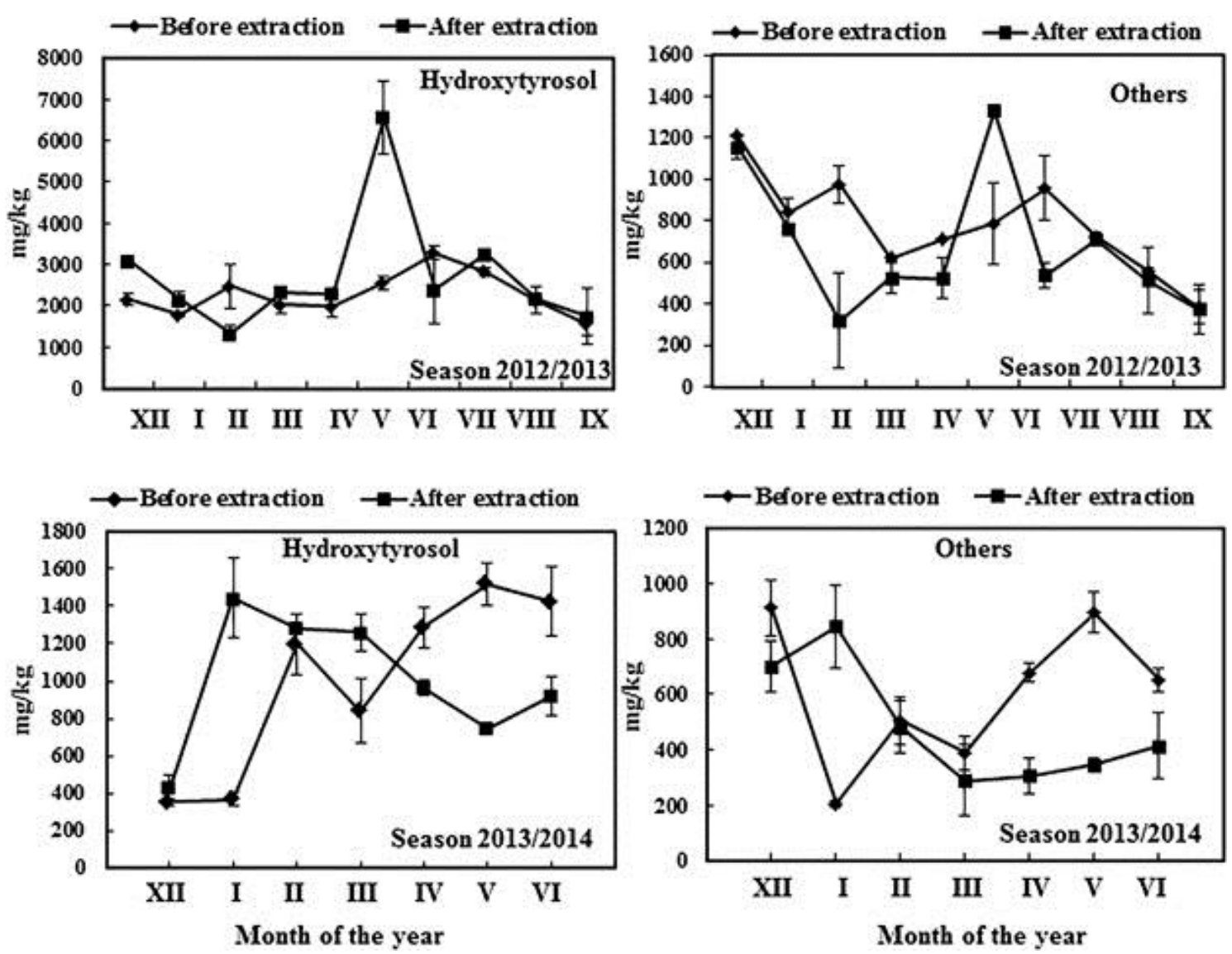